Check for updates

Cite this: RSC Adv., 2019, 9, 2309

Received 9th December 2018 Accepted 2nd January 2019

DOI: 10.1039/c8ra10110h

rsc.li/rsc-advances

\section{Optimization of a bioelectrochemical system for 2,4-dichloronitrobenzene transformation using response surface methodology}

\author{
Hui Chen, ${ }^{a}$ Donghui Lu, ${ }^{a}$ Caiqin Wang, ${ }^{a}$ Linlin Chen, ${ }^{a}$ Xiangyang $\mathrm{Xu}^{\mathrm{abc}}$ \\ and Liang Zhu iD *abc
}

In the present study, a bioelectrochemical system (BES) was developed for 2,4-dichloronitrobenzene (DCINB) transformation. Response surface methodology (RSM) was applied to optimize the operational conditions, including the V/S ratio (volume of the BES/size of the electrode ratio), interval (D) (distance between the anode and cathode) and position ( $P$ ) (proportion of the electrodes immerged in the sludge). The optimum conditions for the $\mathrm{V} / \mathrm{S}$ ratio, interval and position were $40,2.31 \mathrm{~cm}$ and 0.42 . The pollutant removal rate and increase in $\mathrm{Cl}^{-}$were $1.819 \pm 0.037 \mathrm{mg} \mathrm{L}^{-1} \mathrm{~h}^{-1}$ and $11.894 \pm 0.180 \mathrm{mg} \mathrm{L}^{-1}$, which were close to the predicted values ( $1.908 \mathrm{mg} \mathrm{L}^{-1} \mathrm{~h}^{-1}$ and $\left.12.485 \mathrm{mg} \mathrm{L}^{-1}\right)$. A continuous experiment indicated that the pollutant removal efficiency in the BES with $50 \%$ of the electrodes immerged in the sludge was $34.6 \%$ and $22.6 \%$ higher than that in the ones with 0 and $100 \%$ of the electrodes immerged in the sludge.

\section{Introduction}

Chloronitrobenzenes (ClNBs), a kind of important raw material used in the pharmaceutical, dye and pesticide industries, are toxic compounds with mutagenic, carcinogenic and teratogenic effects. $^{\mathbf{1 , 2}}$ They pose a serious threat to human beings and livestock by causing liver disease, hemolytic anemia, etc. ${ }^{3}$

Bioelectrochemical conversion, which combines biodegradation with electrochemical reduction, has been proven to be an alternative method for contaminant detoxification in recent years. ${ }^{4}$ Bioelectrochemical systems (BESs) are innovative and energy saving compared with the conventional anaerobic and electrochemical processes. This technology has been successfully used in the degradation of substituted aromatic compounds, e.g., azo dyes, chloroethenes, chloronitrobenzenes (ClNBs), etc. ${ }^{5-9}$ Extracellular electron transfer related genes which may be responsible for enhanced organohalide-respiration and cathoderespiration activities could be enriched in BESs, contributing to aromatic compound degradation. ${ }^{\mathbf{1 0}}$ Our previous studies confirmed the feasibility of a coupled bioelectrochemical process for the treatment of ClNB-containing wastewater. The 4-ClNB and 2,4-DClNB removal efficiencies in the coupled system were much higher than those of the control; meanwhile, dechlorination-

${ }^{a}$ Institute of Environment Pollution Control and Treatment, Department of Environmental Engineering, Zhejiang University, Hangzhou 310058, China. E-mail: felix79cn@hotmail.com; Fax: +8657188982343; Tel: +8657188982343

${ }^{b}$ Zhejiang Province Key Laboratory for Water Pollution Control and Environmental Safety, Hangzhou 310058, China

${ }^{c}$ Zhejiang Provincial Key Laboratory of Water Pollution Control, 388 Yuhangtang Road, Hangzhou 310058, China related microbes were enriched in the presence of an external voltage.,11 Recently, Sun et al. have investigated the effects of some key parameters on azo dye reduction, including initial pollutant concentration, applied voltage and co-substrates. ${ }^{12}$ In another study treating 2,4-dinitrochlorobenzene using a BES, the effects of voltage, hydraulic retention time (HRT) and salinity were investigated. ${ }^{13}$ However, studies on the optimization of the electrochemical parameters in a system for treating ClNBcontaining wastewater are limited, especially related to the optimization of the electrode-related parameters. Response surface methodology (RSM), a set of mathematical techniques describing the relation between independent variables and responses, was developed by Box and Wilson in the 1950s. ${ }^{14,15}$ Nowadays, RSM has been widely used for designing experimental models and determining the optimum experimental conditions. ${ }^{16-19}$

In this study, the objective was to characterize the main parameters in the bioelectrochemical process, including the $\mathrm{V} / \mathrm{S}$ ratio (volume of the BES/size of the electrode ratio), interval $(D)$ (distance between the anode and cathode) and position $(P)$ (proportion of the electrodes immerged in the sludge). The experiments were conducted in a batch assay to optimize the $\mathrm{V} / \mathrm{S}$ ratio, interval and position to achieve the best performance in pollutant transformation. The evaluation was conducted with central composite design (CCD), a common type of RSM.

\section{Materials and methods}

\subsection{Experimental set-up}

The experiments were conducted in single-chambered microbial electrolysis fuels (BES) with a volume of $480 \mathrm{~mL}(6 \times 8 \times 10$ $\mathrm{cm}$ ) in batch assays (Fig. 1). A pair of graphite felt electrodes 


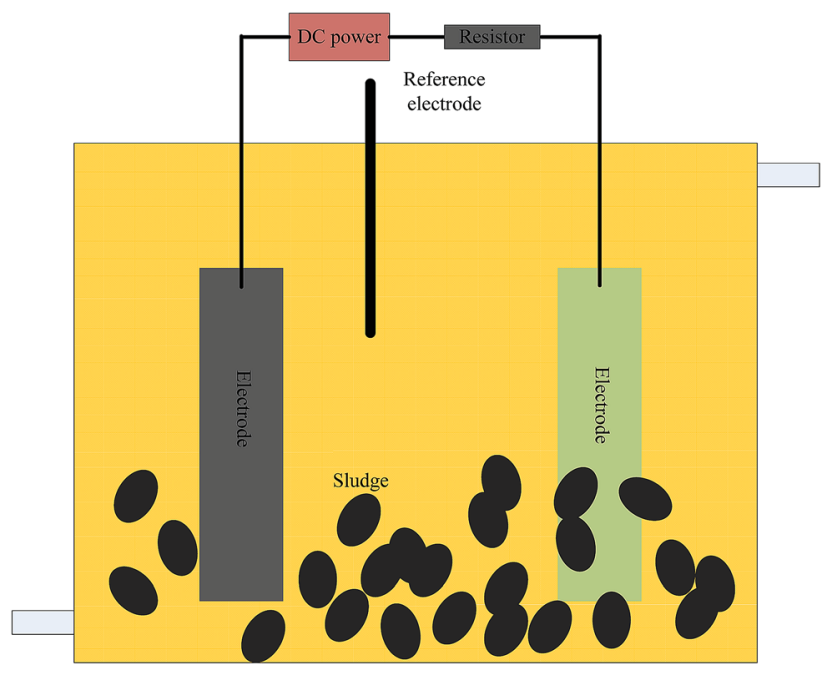

Fig. 1 Schematic diagram of the reactor configuration.

(Beijing Sanye Carbon Co., China) was used and the size was set according to the $V / S$ (volume of the BES to the size of the electrode). A $1.5 \mathrm{~V}$ external electric field was added with a direct current power source (Victory3003D, China). A $10 \Omega$ resistor was used in the circuit.

\subsection{Synthetic wastewater}

Synthetic wastewater was used in this study and the composition is described in our previous study. ${ }^{1}$ 2,4-Dichloronitrobenzene (DClNB) was used as the target pollutant and an initial dose of $50 \mathrm{mg} \mathrm{L}^{-1}$ was used in the assays. The BESs were inoculated with sludge taken from a steadily operated upflow anaerobic sludge blanket (UASB) in the lab.

\subsection{Analytical method}

DClNB and $\mathrm{Cl}^{-}$were measured by high-performance liquid chromatography (HPLC) (Waters 2487, USA) and $\mathrm{Cl}^{-}$was monitored by ion chromatography (IC) (Dionex 1100, USA) according to Chen et al. ${ }^{1}$

The fluorescence staining technique and confocal laser scanning microscopy (CLSM) (ZEISS, LSM710 NLO, Germany) were used to observe the distribution of live and dead cells. A LIVE/DEAD BacLight Bacterial Viability Kit (Invitrogen, CA, USA) was dissolved in $5 \mathrm{~mL}$ of sterile deionized water and mixed with equal bacterial suspension. The sample was placed under dark conditions for 15 min and observed by CLSM.

Electrochemical impedance spectroscopy (EIS) was also conducted on an electrochemical workstation to analyze the resistance of the reactor. A two-electrode system was used to measure the resistance of the whole reactor. The anode was used as the working electrode and the cathode was used as the counter electrode and reference electrode. The testing frequency ranged from $10^{-2}$ to $10^{5} \mathrm{~Hz}$ with an amplitude of $5 \mathrm{mV}$.

\subsection{Experimental design}

For the response surface models, the independent variables were $V / S\left(X_{1}\right), D\left(X_{2}\right)$ and $P\left(X_{3}\right)$ and $-1,0$ and +1 represented the low, center and high level of each variable. The DCINB removal rate $\left(Y_{1}\right)$ and $\Delta \mathrm{Cl}^{-}\left(Y_{2}\right)$ were the dependent variables. The design and results of the experiments are presented in Table 1. The significance of the coefficient of the models was determined using $p$-values and the response variables were considered to be significant when $p$ was below 0.05 .

\section{Results and discussion}

\subsection{Overview of the response models}

Fitting of empirical models to the experimental data was conducted by RSM to describe the characteristics of the response. The mathematical-statistical relationship between the independent variables $(X)$ and the response function $(Y)$ is as follows:

Table 1 Summary of the independent and dependent variables

\begin{tabular}{|c|c|c|c|c|c|}
\hline Run & $X_{1}^{a}(V / S)$ & $X_{2}: D^{b}(\mathrm{~cm})$ & $X_{3}: P^{c}$ & $Y_{1}:$ removal rate $\mathrm{mg}^{-1} \mathrm{~h}^{-1}$ & $Y_{2}\left(\Delta \mathrm{Cl}^{-1}\right) \mathrm{mg} \mathrm{L}^{-1}$ \\
\hline 1 & 40 & 3 & 0.5 & 1.885 & 11.721 \\
\hline 2 & 20 & 2 & 1 & 1.569 & 9.513 \\
\hline 3 & 30 & 2 & 0.5 & 1.969 & 12.494 \\
\hline 4 & 40 & 1 & 0.5 & 1.775 & 11.353 \\
\hline 5 & 30 & 2 & 0.5 & 1.952 & 12.728 \\
\hline 6 & 30 & 1 & 1 & 1.533 & 9.255 \\
\hline 7 & 20 & 1 & 0.5 & 1.863 & 11.935 \\
\hline 8 & 20 & 3 & 0.5 & 1.623 & 9.789 \\
\hline 9 & 40 & 2 & 0 & 1.646 & 11.095 \\
\hline 10 & 40 & 2 & 1 & 1.616 & 9.860 \\
\hline 11 & 30 & 2 & 0.5 & 1.919 & 12.788 \\
\hline 12 & 20 & 2 & 0 & 1.677 & 10.286 \\
\hline 13 & 30 & 1 & 0 & 1.733 & 10.654 \\
\hline 14 & 30 & 3 & 1 & 1.494 & 9.145 \\
\hline 15 & 30 & 3 & 0 & 1.722 & 10.703 \\
\hline
\end{tabular}

${ }^{a}$ Volume of the MEC/size of the electrode. ${ }^{b}$ Distance between the electrodes. ${ }^{c}$ Position of the electrode. 
Table 2 ANOVA test for response function $Y_{\text {removal rate }}{ }^{a}$

\begin{tabular}{|c|c|c|c|c|c|c|}
\hline Source & Sum of squares & df & Mean square & $F$ value & $\begin{array}{l}p \text {-value, } \\
\text { prob }>F\end{array}$ & \\
\hline Model & 0.32 & 9 & 0.036 & 11.48 & 0.0076 & Significant \\
\hline$B-D$ & $4.050 \times 10^{-3}$ & 1 & $4.050 \times 10^{-3}$ & 1.29 & 0.3097 & \\
\hline$C-P$ & 0.040 & 1 & 0.040 & 12.73 & 0.0161 & \\
\hline$A B$ & 0.031 & 1 & 0.031 & 9.74 & 0.0262 & \\
\hline$A^{2}$ & 0.022 & 1 & 0.022 & 6.93 & 0.0464 & \\
\hline$B^{2}$ & 0.026 & 1 & 0.026 & 8.15 & 0.0356 & \\
\hline$C^{2}$ & 0.22 & 1 & 0.22 & 69.23 & 0.0004 & \\
\hline Residual & 0.016 & 5 & $3.145 \times 10^{-3}$ & & & \\
\hline Lack of fit & 0.014 & 3 & $4.811 \times 10^{-3}$ & 7.44 & 0.1207 & Not significant \\
\hline Pure error & $1.293 \times 10^{-3}$ & 2 & $6.463 \times 10^{-4}$ & & & \\
\hline
\end{tabular}

$Y=b_{0}+b_{1} X_{1}+b_{2} X_{2}+b_{3} X_{3}+b_{12} X_{12}+b_{13} X_{13}+b_{23} X_{23}+b_{11} X_{1}^{2}$ $+b_{22} X_{2}^{2}+b_{33} X_{3}^{2}$

where $X_{1}, X_{2}$ and $X_{3}$ represent the $V / S$ ratio, interval and position, respectively.

Eqn (2) and (3) describe the response functions for $\Delta \mathrm{Cl}^{-}$and DCINB removal rate.

$$
\begin{aligned}
Y_{\Delta \mathrm{Cl}^{-}}= & 5.34962+0.28355 X_{1}+1.36388 X_{2}+7.09425 X_{3}+ \\
& 0.06285 X_{12}-0.0231 X_{13}-0.0795 X_{23}-6.10625 \times \\
& 10^{-3} X_{1}{ }^{2}-0.85988 X_{2}{ }^{2}-7.4835 X_{3}{ }^{2} \\
& \left(R^{2}=0.9757\right)
\end{aligned}
$$

$Y_{\text {removal rate }}=1.293+0.02902 X_{1}+0.05533 X_{2}+0.74083 X_{3}+8.75$

$$
\begin{aligned}
& \times 10^{-3} X_{12}+3.9 \times 10^{-3} X_{13}-0.014 X_{23}-7.68333 \\
& \times 10^{-4} X_{1}^{2}-0.08333 X_{2}^{2}-0.97133 X_{3}^{2} \\
& \left(R^{2}=0.9538\right)
\end{aligned}
$$

The closer the correlation coefficient $\left(R^{2}\right)$ is to 1 , the more accurate the polynomial equation will be. ${ }^{20}$ The calculated $R^{2}$ (0.9757 and 0.9538) indicated that the predictions of the response function were in line with the experimental one at the confidence level of $95 \%$. The absolute value of the coefficient of $X_{2}$ is significantly higher than that of the other variables, indicating that the proportion of the electrodes immerged in the sludge is the main factor controlling the $\Delta \mathrm{Cl}^{-}$and DClNB removal rate.

The variance analyses (ANOVA) in Tables 2 and 3 describe the fitting results for the response surface model. The significance of the model is judged by the $F$-value and $p$-value. The $F$ -

\begin{tabular}{|c|c|c|c|c|c|c|}
\hline Model & 21.4 & 9 & 2.38 & 22.26 & 0.0016 & Significant \\
\hline$B-D$ & 0.42 & 1 & 0.42 & 3.96 & 0.1033 & \\
\hline$C-P$ & 3.08 & 1 & 3.08 & 28.85 & 0.0030 & \\
\hline$A B$ & 1.58 & 1 & 1.58 & 14.79 & 0.0120 & \\
\hline$A^{2}$ & 1.38 & 1 & 1.38 & 12.89 & 0.0157 & \\
\hline$B^{2}$ & 2.73 & 1 & 2.73 & 25.56 & 0.0039 & \\
\hline$C^{2}$ & 12.92 & 1 & 12.92 & 121.00 & 0.0001 & \\
\hline Residual & 0.53 & 5 & 0.11 & & & \\
\hline Lack of fit & 0.49 & 3 & 0.16 & 6.71 & 0.1324 & Not significant \\
\hline Pure error & 0.048 & 2 & 0.024 & & & \\
\hline
\end{tabular}
value represents the ratio of regression mean square to the estimated parameter standard deviation, while the $p$-value is the probability of the occurrence of the $F$-value. ${ }^{21}$ Both models are significant in this study ( $p$-values are 0.0076 and 0.0016 ). The results indicate that the terms $X_{3}$ and $X_{3}{ }^{2}$ are significant with $p$ -

Table 3 ANOVA test for response function $Y_{\Delta \mathrm{Cl}^{-}}{ }^{a}$

${ }^{a} R^{2}=0.9757 ;$ Adj $R^{2}=0.9318 ;$ Pred $R^{2}=0.6407$. 
values below 0.05 , indicating that the position of the electrodes is the most important factor affecting the DClNB removal rate and $\Delta \mathrm{Cl}^{-}$. The results are in agreement with those of the coefficient analyses.

The three-dimensional (3D) response surface plots are presented in Fig. 2. The interaction effects of two variables on the response functions are revealed in these plots. Fig. 2A and B describe the interaction of the $V / S$ ratio with the interval when $50 \%$ of the electrodes are immerged in the sludge. Fig. $2 \mathrm{C}$ and $2 \mathrm{D}$ represent the interaction of the $V / S$ ratio with the electrode position when the interval between the electrodes is $2 \mathrm{~cm}$. Fig. $1 \mathrm{E}$ and $\mathrm{F}$ represent the interaction of the electrode position with the interval when the $V / S$ ratio is at the center point of 30 . Each plot exhibits an obvious peak, indicating that the optimal point was well concluded as inside the design boundary. ${ }^{22}$ It has been reported that the contour plots reflect the strength of the interaction between the variables. The interaction can be ignored if the contour lines are close to a circle. On the contrary, the interaction is strong if the contour lines look like ellipses. ${ }^{23}$ As depicted in Fig. 2A and B, the contour lines are close to
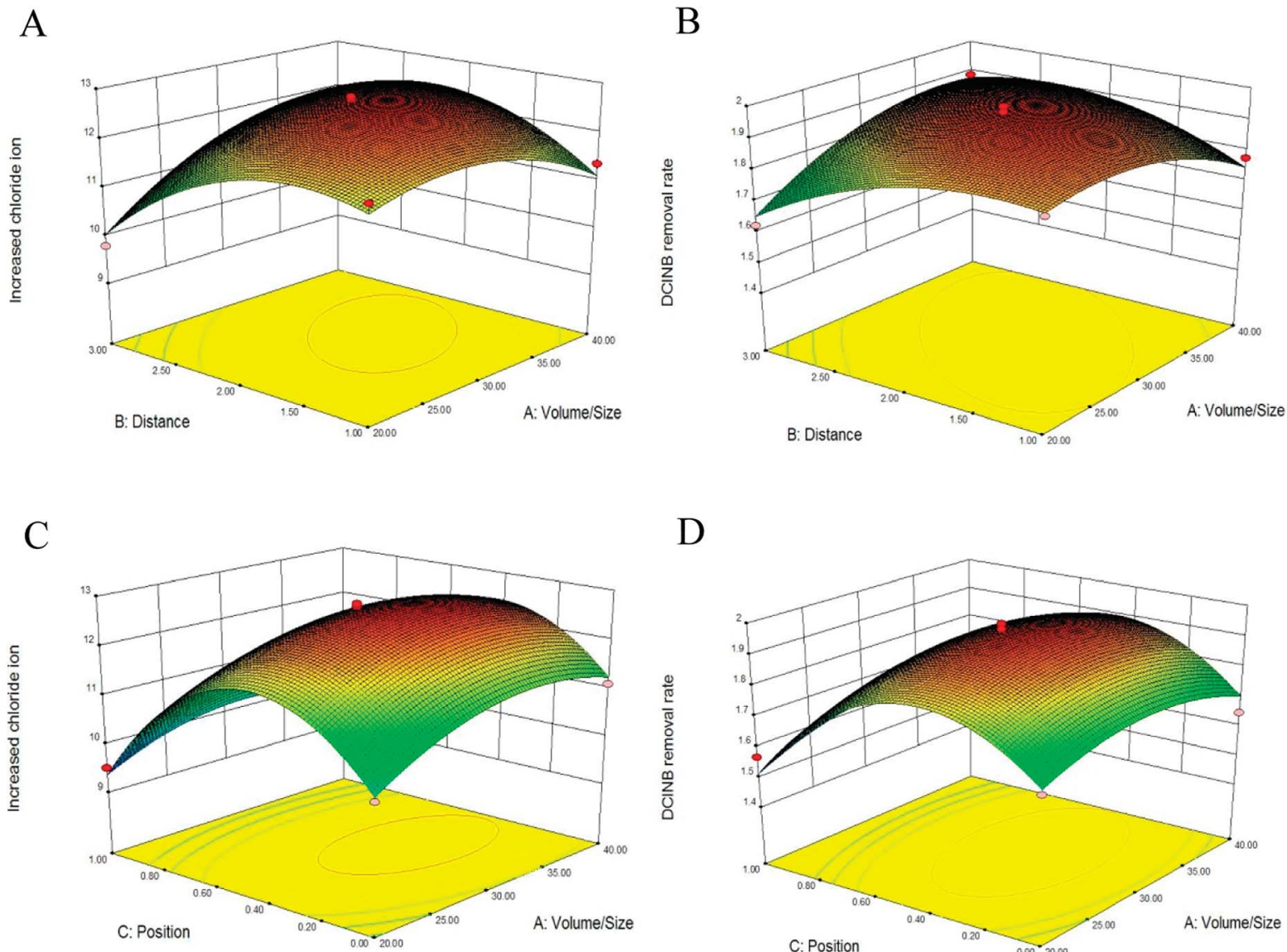

D

$\mathrm{E}$
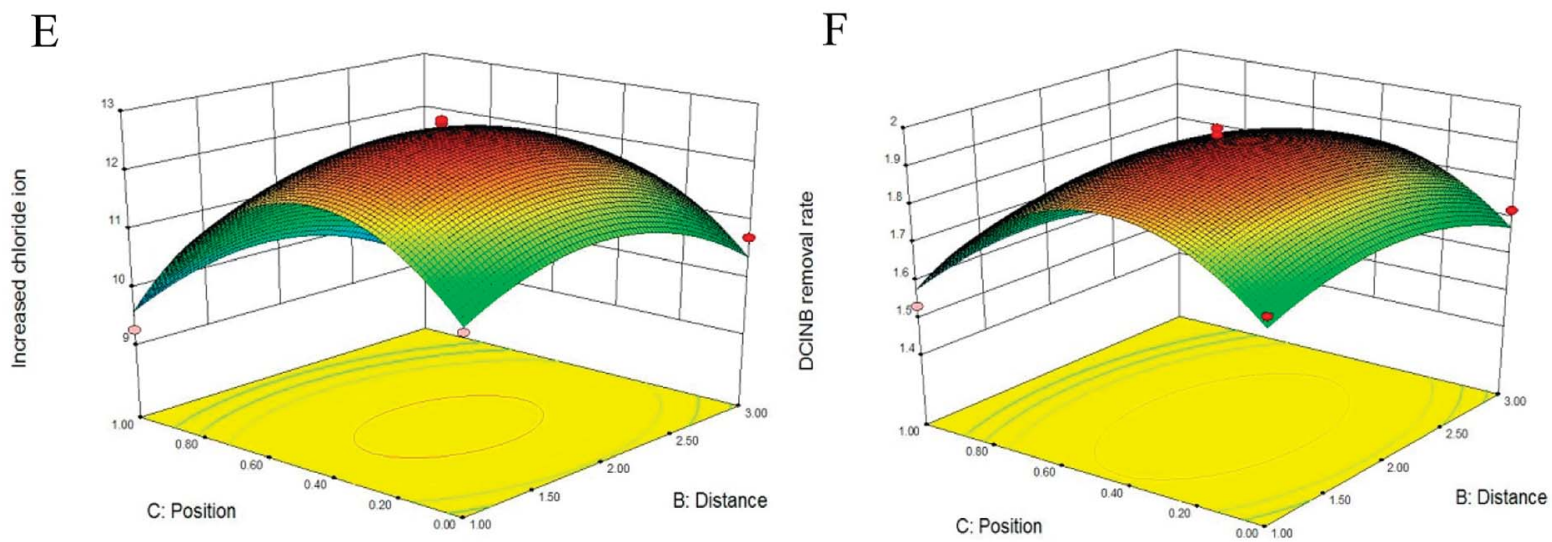

Fig. 2 Three-dimensional response surface plots. Effect of volume/size ratio and distance on $\Delta \mathrm{Cl}^{-}(\mathrm{A})$ and $\mathrm{DCINB}$ removal rate (B); effect of volume/size ratio and position on $\Delta \mathrm{Cl}^{-}$(C) and DCINB removal rate (D); effect of distance and position on $\Delta \mathrm{Cl}^{-}(\mathrm{E})$ and $\mathrm{DCINB}$ removal rate (F). 
circles, indicating that the interaction between the interval and $V / S$ ratio can be ignored. The contour lines in Fig. 2C-F are close to ellipses, indicating that the interactions between the position and $V / S$ ratio, and the position and interval were strong.

\subsection{Validation of the regression model}

In order to achieve the maximum DClNB removal rate and $\Delta \mathrm{Cl}^{-}$, the optimum parameters were used according to the RSM. The $V / S$ ratio, interval and position were $31.75,1.95 \mathrm{~cm}$ and $42 \%$, respectively. The experiment was conducted in triplicate. The results indicated that the DClNB removal rate and $\Delta \mathrm{Cl}^{-}$were $1.819 \pm 0.037 \mathrm{mg} \mathrm{L}^{-1} \mathrm{~h}^{-1}$ and $11.894 \pm 0.180 \mathrm{mg} \mathrm{L}^{-1}$, respectively. The deviations from the predicted values were both below $5 \%$, indicating that the regression was applicable for predicting the DClNB removal rate and $\Delta \mathrm{Cl}^{-}$.

\subsection{The effect of electrode position on reactor performance}

According to the results above, electrode position was the key factor influencing reactor performance. Therefore, a continuous experiment was conducted with three BESs. The electrodes of the BESs were immerged in the sludge $0 \%, 50 \%$ and $100 \%$, while the interval between the electrodes and the $V / S$ were $2 \mathrm{~cm}$ and 40 . The COD and DClNB concentration were maintained at 500 and $100 \mathrm{mg} \mathrm{L}^{-1}$. The reactor performances were compared from the perspectives of current, pollutant transformation, EIS, etc.

3.3.1 Differences in DClNB transformation. DClNB transformation highly depended on the electrode position (Fig. 3). The DClNB removal efficiencies in the $0 \%, 50 \%$ and $100 \%$ immerged reactors were $56.1 \pm 2.7 \%, 75.5 \pm 2.1 \%$ and $61.5 \pm$ $2.2 \%$, respectively. The $50 \%$ immerged electrodes had the best performance, followed by the 0 and 100\% immerged ones. The results indicated that having an appropriate proportion of the electrodes immerged in the sludge could effectively improve pollutant transformation. Kong et al. reported that in a reactor with $1 / 4$ soaking electrode, the functional microbes in the sludge could migrate to the upper part of the electrode more easily, contributing to the formation of a biofilm on the

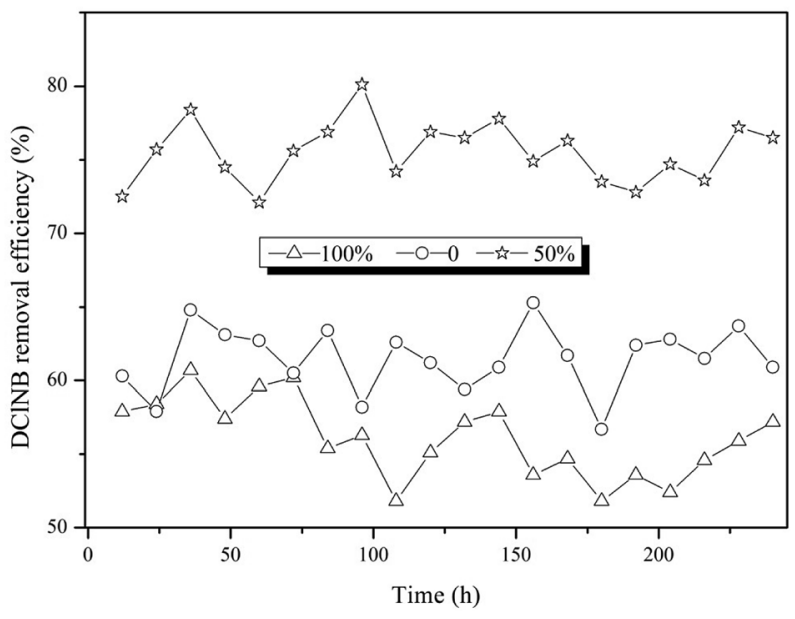

Fig. 3 The effect of electrode position on pollutant removal. electrode surface. ${ }^{24}$ This might be related to the electron transfer through the electrode. However, the biofilms on the over-immerged electrodes, which might not be bioelectrocatalytically active, would exhibit electron transfer resistance. Moreover, large amounts of biomass that could restrict the mass transfer process might be developed. ${ }^{25}$

3.3.2 Differences in current. As discussed above, the thickness of the biofilm might lead to differences in electron transfer between the electrodes and electron acceptors. Fig. 4 reveals the current in the $0 \%, 50 \%$ and $100 \%$ immerged reactors $(6.47 \pm$ $0.15,6.59 \pm 0.09$ and $4.42 \pm 0.08 \mathrm{~mA}$ ). The highest current was observed for the $50 \%$ immerged reactor, which was 1.5 -fold that of the $100 \%$ immerged reactor. This might be due to the fact that the microbes attached to the $50 \%$ immerged electrode had higher microbial activity, leading to the evolution of the microbial community and diversity. ${ }^{26}$ The current generation in the BES was reported to be influenced by the transfer of protons, substrate and metabolites between the solution and electrodes. ${ }^{27}$ Hence, the differences in electrode position might result in different transfer capacities, leading to differences in current generation. The microbes in the $50 \%$ immerged electrode might have higher electroactivity, which would be beneficial to the electron transfer between the electrodes and microbes, resulting in higher current generation. Michie et al. reported that mass transfer and biocatalytic reactions would be inhibited with overthick biofilms. ${ }^{25}$ Therefore, the biofilms were observed by confocal laser scanning microscopy (CLSM) to reveal if there was any difference in biofilm characteristics (Fig. 5). The CLSM graphs indicated that most dead microbes were located in the inner layer of the biofilm, while living microbes were located in the outer layer. It was found in Fig. 4 that the 100\% immerged reactor had the thickest biofilm and this was in accordance with the results above, i.e., the over-thick biofilm reduced the current density and pollutant removal efficiency.

3.3.3 Differences in EIS. EIS was conducted and a Bode graph was used to describe the relationship between the resistance and frequency. Fig. 6 indicates that the resistance of the $100 \%$ immerged reactor is much higher that of the other ones

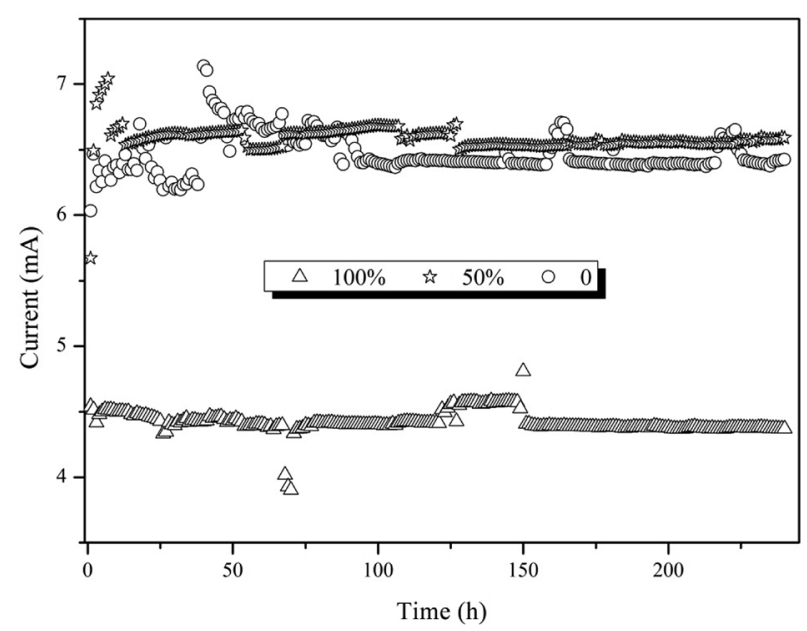

Fig. 4 The effect of electrode position on the current. 

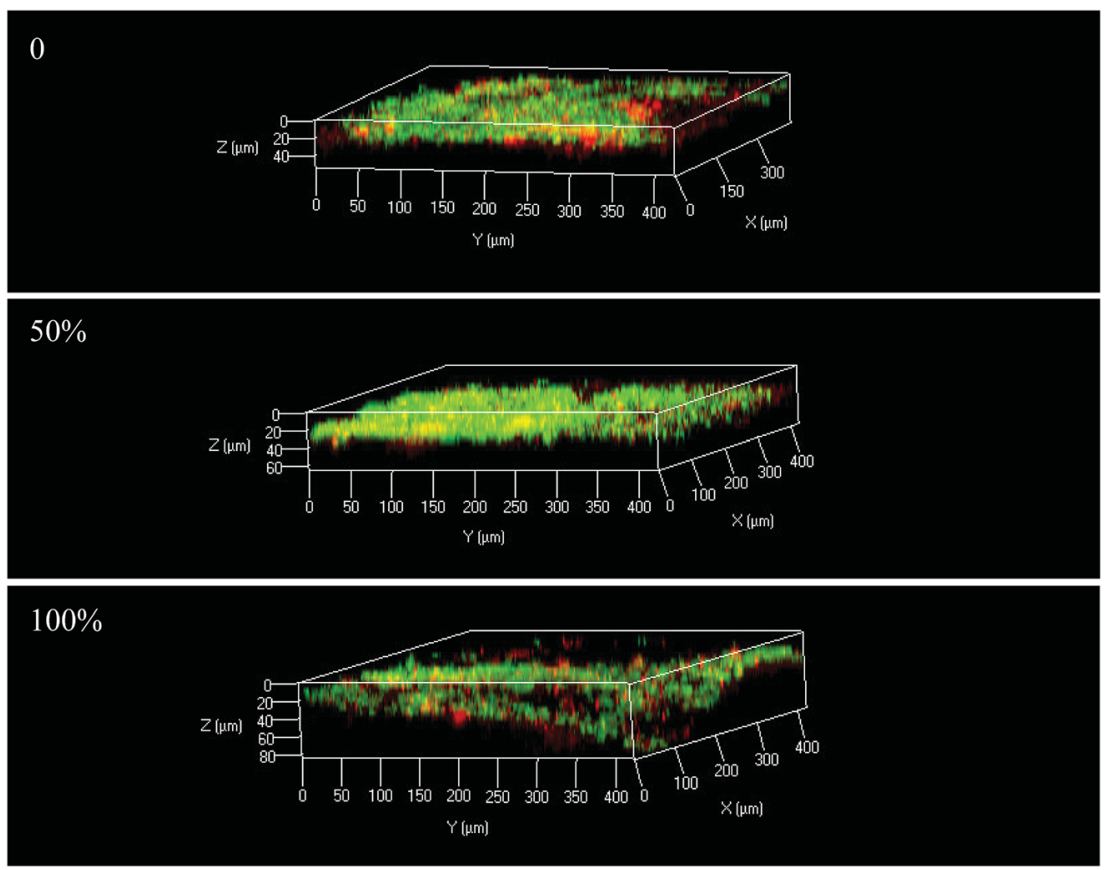

Fig. 5 CLSM graphs of the electrode biofilms.

(398.1 $\Omega$ vs. $134.9 \Omega$ and $158.5 \Omega$ ). The low-frequency region represents the resistance in charge transfer and the higher the value is, the slower the charge transfer. A higher value in this region can be attributed to slower kinetics of charge transfer reactions associated with the redox process ${ }^{28}$ confirming that the $100 \%$ immerged electrode had higher impedance than the other electrodes. This indicated that when the electrode was placed in bulk solution ( $0 \%$ immerged) or $1 / 2$ part in the sludge $(50 \%$ immerged), the electrochemical reaction would be accelerated for efficient electron transfer. However, when the electrode was totally immerged in the sludge, microbes would attach on the surface of the electrode to form a thick biofilm, reducing the effective contact area of the electrode with the pollutant, and leading to a decrease in pollutant transformation. ${ }^{24}$

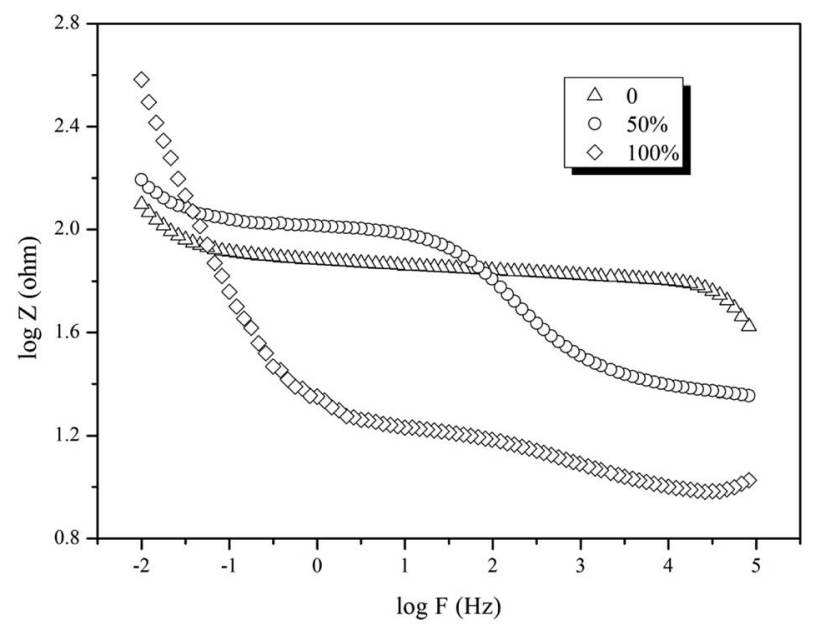

Fig. 6 Effect of electrode position on the electrochemical characteristics.
Taking the results above together, electrode position influences the formation of the biofilm, leading to differences in resistance, current and pollutant removal efficiency. The overthick biofilm in the $100 \%$ reactor would inhibit pollutant transformation. Hence, the proportion of the electrode immerged in the sludge should be further investigated in future research.

\section{Conclusions}

Response surface methodology (RSM) was applied to optimize the operational conditions and the optimum conditions for the $V / S$ ratio, interval and position were $40,2.31 \mathrm{~cm}$ and 0.42 . The pollutant removal rate and increased $\mathrm{Cl}^{-}$achieved under these conditions were close to the predicted ones, indicating the feasibility of the model for the prediction of DClNB transformation in the BES. DCINB transformation was inhibited when the electrodes were completely immerged in the sludge due to over-thick biofilms. Specifically, the resistance increased when the electrodes were completely immerged in the sludge, leading to a decrease in the current and pollutant removal efficiency. The current study confirms the feasibility of RSM for the optimization of DCINB transformation in a lab-scale BES, but more scaled-up studies should be conducted in the future.

\section{Conflicts of interest}

There are no conflicts to declare.

\section{Acknowledgements}

This work was funded by the National Natural Science Foundation of China (No. 51678519), the Major Science and Technology Program for Water Pollution Control and Treatment 
(2017ZX07206-002), Zhejiang Province Science and Technology Projects (2018C03003) and the National Natural Science Foundation of China (No. 51378454).

\section{References}

1 H. Chen, X. Y. Gao, C. Q. Wang, J. J. Shao, X. Y. Xu and L. Zhu, Bioresour. Technol., 2017, 241, 879-886.

2 L. L. Chen, J. J. Shao, H. Chen, C. Q. Wang, X. Y. Gao, X. Y. Xu and L. Zhu, Bioresour. Technol., 2018, 254, 180-186.

3 X. B. $\mathrm{Hu}, \mathrm{W} . \mathrm{H}$. Zheng and R. F. Zhang, J. Solid State Electrochem., 2016, 20, 3323-3330.

4 X. H. Peng, X. H. Pan, X. Wang, D. Y. Li, P. F. Huang, G. H. Qiu, K. Shan and X. Z. Chu, Bioresour. Technol., 2018, 249, 844-850.

5 H. J. Feng, X. Q. Zhang, Y. X. Liang, M. Z. Wang, D. S. Shen, Y. C. Ding, B. C. Huang and J. L. Shentu, Water Res., 2014, 60, 54-63.

6 D. Y. Kong, B. Liang, D. J. Lee, A. J. Wang and N. Q. Ren, J. Environ. Sci., 2014, 26, 1689-1697.

7 J. Y. Shen, Y. Y. Zhang, X. P. Xu, C. X. Hua, X. Y. Sun, J. S. Li, Y. Mu and L. J. Wang, Water Res., 2013, 47, 5511-5519.

8 D. S. Shen, X. Q. Zhang, H. J. Feng, K. Zhang, K. Wang, Y. Y. Long, M. Z. Wang and Y. F. Wang, Bioresour. Technol., 2014, 172, 104-111.

9 H. C. Wang, H. Y. Cheng, S. S. Wang, D. Cui, J. L. Han, Y. P. Hu, S. G. Su and A. J. Wang, J. Environ. Sci., 2016, 39, 198-207.

10 F. Chen, Z. L. Li, J. Q. Yang, B. Liang, X. Q. Lin, J. Nan and A. J. Wang, Chem. Eng. J., 2018, 352, 730-736.

11 X. Y. Xu, J. J. Shao, M. Y. Li, K. T. Gao, J. Jin and L. Zhu, Bioresour. Technol., 2016, 218, 1037-1045.
12 Q. Sun, Z. L. Li, W. Z. Liu, D. Cui, Y. Z. Wang, J. S. Chung and A. J. Wang, Int. J. Electrochem. Sci., 2016, 11, 2447-2460.

13 X. B. Jiang, J. Y. Shen, Y. Han, S. Lou, W. Q. Han, X. Y. Sun, J. S. Li, Y. Mu and L. J. Wang, Water Res., 2016, 88, 257-265.

14 G. E. P. Box and K. B. Wilson, J. R. Stat. Soc. Series B Stat. Methodol., 1951, 13, 1-45.

15 M. A. Bezerra, R. E. Santelli, E. P. Oliveira, L. S. Villar and L. A. Escaleira, Talanta, 2008, 7, 965-977.

16 F. Ghorbani, H. Younesi, S. M. Ghasempouri, A. A. Zinatizadeh, M. Amini and A. Daneshi, Chem. Eng. J., 2008, 145, 267-275.

17 H. Chen, J. J. Yu, X. Y. Jia and R. C. Jin, Chemosphere, 2014, 117, 610-616.

18 B. S. Kaith, R. Sharma, S. Kalia and M. S. Bhatti, RSC Adv., 2014, 4, 40339-40344.

19 G. Y. Wang, S. R. Zhang, T. Li, X. X. Xu, Q. M. Zhong, Y. Chen, O. P. Deng and Y. Li, RSC Adv., 2015, 5, 58010-58018.

20 B. L. Liu and Y. M. Tzeng, Bioprocess Eng., 1998, 18, 413-418.

21 U. Guyo, T. Makawa, M. Moyo, T. Nharingo, B. C. Nyamunda and T. Mugadza, J. Environ. Chem. Eng., 2015, 3, 2472-2483.

22 J. Jang and D. S. Lee, Sci. Total Environ., 2018, 615, 549-557.

23 R. V. Muralidhar and R. R. Chirumamila, Biochem. Eng. J., 2001, 9, 17-23.

24 F. Y. Kong, A. J. Wang and H. Y. Ren, Bioresour. Technol., 2015, 192, 486-493.

25 I. S. Michie, J. R. Kim, R. M. Dinsdale, A. J. Guwy and G. C. Premier, Bioresour. Technol., 2014, 165, 13-20.

26 D. Pant, G. Van Bogaert, L. L. Diel and K. Vanbroekhoven, Bioresour. Technol., 2010, 101, 1533-1543.

27 C. I. Torres, A. K. Marcus and B. E. Rittmann, Biotechnol. Bioeng., 2008, 100, 872-881.

28 Z. He and F. Mansfeld, Energy Environ. Sci., 2009, 2, 215-219. 